\title{
MÉTODO DA RESISTÊNCIA CONTÍNUA COMO ALTERNATIVA PARA O DIMENSIONAMENTO DE ESTRUTURAS EM AÇO INOXIDÁVEL
}

\author{
Rafaelle Cavalcanti Ribeiro Galvão \\ Graduanda em Engenharia Civil pelo Centro Federal de Educação Tecnológica Celso Suckow da \\ Fonseca (CEFET-RJ), Rio de Janeiro, RJ, Brasil \\ rafaellecrg@gmail.com \\ João de Jesus dos Santos \\ Doutor em Estruturas pela Pontifícia Universidade Católica (PUC-Rio), Rio de Janeiro, RJ, Brasil \\ paraduc@yahoo.com.br
}

\section{RESUMO}

O projeto que originou este artigo objetiva demonstrar os benefícios alcançados através da utilização de um método de cálculo estrutural inovador - o Método da Resistência Continua (MRC) - na engenharia civil. Este é um método que levará em consideração a curva de comportamento mecânico do aço inoxidável, visto que alguns materiais, como os aços de alta resistência, não apresentam um patamar de escoamento. Autores referenciados no projeto como Gardner (2002) e Santos (2014) sugerem a utilização do Método da Resistência Contínua (MRC) que, atualmente, possibilita avaliar a utilização da fase de encruamento, através do comportamento diferenciado entre o aço carbono e o aço inoxidável. Esta análise tem por objetivo demonstrar que a característica de resistência contínua do aço inoxidável pode ser usada para diminuir a área da seção estrutural e gerar economia, sem comprometer a segurança. Este aço de alta resistência, então, é uma alternativa sustentável na engenharia civil que, através do custo e benefício, a longo prazo, aliado à grande resistência que ele apresenta, possibilitará uma maior reutilização de material. 0 alto custo inicial em relação ao aço carbono também poderá ser reduzido em função da aplicação desse novo método de cálculo.

Palavras-chave: Aço Inoxidável. Endurecimento por Encruamento. Eurocode. Estruturas Metálicas.

CONTINUOUS STRENGTH METHOD AS ALTERNATIVE FOR STAINLESS STEEL STRUCTURES DESIGN

\begin{abstract}
The project which originated this article aims to demonstrate the benefits achieved through the use of an innovative structural calculation method - the Continuous Strength Method (CSM) - in civil engineering. This is a method that will take into account the mechanical behavior curve of the of stainless steel, since some materials, such as high-strength steels, do not have a yield plateau. Authors referenced in this project, such as Gardner (2002) and Santos (2014), suggest the use of the Continuous Strength Method (CSM) which, currently, enables the consideration of the hardening phase, through the differentiated behavior between the carbon steel and the stainless steel. This analysis aims to demonstrate that the continuous strength characteristic of stainless steels can be used to reduce the structural section and to generate savings, without compromising safety. This high-strength steel, then, is a sustainable alternative in civil engineering that, through its long-term cost and benefit, combined with its greater strength, enables greater material reuse. The high initial cost when compared to carbon steel can also be reduced by applying this new calculation method.
\end{abstract}

Keywords: Stainless Steel. Strain Hardening. Eurocode. Metallic Structures. 


\section{INTRODUÇÃO}

O Método da Resistência Contínua vem sendo proposto por pesquisadores de todo o mundo para o dimensionamento de estruturas em aço inoxidável. O uso desse tipo de material em projetos estruturais ainda é considerado uma alternativa ambiciosa devido, especialmente, ao seu alto preço no mercado. Se comparado ao aço carbono que, normalmente, é utilizado quando se opta por uma estrutura metálica, o preço do aço inoxidável do tipo austenítico 304 - o mais comum no mercado e mais recomendado para uso estrutural, devido a sua alta ductilidade e boa soldagem - é cerca de $280 \%$ mais alto, como apresentado no Quadro 1.

Quadro 1: Comparativo de Preços do Aço Carbono e Aço Inoxidável Austenítico 304

\begin{tabular}{|c|c|c|c|c|}
\hline \multicolumn{5}{|c|}{ PREÇO COMPARATIVO AÇO CARBONO E AÇO INOXIDÁVEL AUSTENÍTICO 304 } \\
\hline DATA & AÇO CARBONO (US\$/ton) & AÇO INOXIDÁVEL 304 (US\$/ton) & DIFERENÇA (US\$/ton) & $\begin{array}{c}\text { DIFERENÇA } \\
\text { (\%) }\end{array}$ \\
\hline abr/20 & 614 & 2314 & 1700 & $276,87 \%$ \\
\hline mar/20 & 642 & 2345 & 1703 & $265,26 \%$ \\
\hline fev/20 & 643 & 2368 & 1725 & $268,27 \%$ \\
\hline jan/20 & 644 & 2391 & 1747 & $271,27 \%$ \\
\hline dez/19 & 620 & 2492 & 1872 & $301,94 \%$ \\
\hline nov/19 & 614 & 2598 & 1984 & $323,13 \%$ \\
\hline out/19 & 621 & 2622 & 2001 & $322,22 \%$ \\
\hline set/19 & 645 & 2547 & 1902 & $294,88 \%$ \\
\hline ago/19 & 657 & 2406 & 1749 & $266,21 \%$ \\
\hline jul/19 & 660 & 2381 & 1721 & $260,76 \%$ \\
\hline jun/19 & 668 & 2406 & 1738 & $260,18 \%$ \\
\hline mai/19 & 687 & 2476 & 1789 & $260,41 \%$ \\
\hline MÉDIAS & 642,92 & $\mathbf{2 4 4 5 , 5 0}$ & $\mathbf{1 8 0 2 , 5 8}$ & $\mathbf{2 8 0 , 9 5 \%}$ \\
\hline
\end{tabular}

Fonte: (WORLD STEEL PRICE, 2021).

No entanto, esse aço de alta resistência possui características especiais em relação ao aço carbono - como a sua baixa necessidade de manutenção proporcionada, principalmente, por sua alta resistência à corrosão - que ajudam a diminuir, a longo prazo, o custo das estruturas metálicas feitas com ele ou manter o custo com um melhor desempenho.

A Golden Gate Bridge, inaugurada em 1937, é composta por aço carbono e já foi superdimensionada para considerar o efeito corrosivo alto no local que sofre com constantes neblinas e alta salinidade. Ainda assim, a ponte está em constante manutenção - a cada 10 ou 20 
anos $^{1}$ - com o processo de reaplicação de uma pintura à base de zinco que serve como metal de sacrifício para a estrutura.

Por outro lado, para a construção da Ponte Stonecutters, em Hong Kong, foi utilizado o aço inoxidável do tipo austenítico S322 e S304² de forma que a previsão de necessidade de manutenção da ponte é de 120 anos desde a conclusão da sua construção. Esta característica de durabilidade tem crescido em importância no mercado da construção civil em que se costumava atentar mais para a importância da resistência mecânica das estruturas.

O aço inoxidável possui diversas características importantes para a utilização metálica na construção civil para fins estruturais: alta ductilidade e homogeneidade, soldabilidade, resistência à corrosão e elevada relação entre limite de ruptura e limite de escoamento. Dessa forma, além de tudo, o aço inoxidável é um material mais em conformidade com as demandas atuais de sustentabilidade na indústria, devido a ter uma maior chance de reaproveitamento e menos uso de outros materiais que são necessários em um trabalho de manutenção.

Atualmente, a metodologia de dimensionamento de estruturas em aço inoxidável é obtida através da necessidade de analogias com o aço carbono, que tem o comportamento mecânico diferente. Dessa maneira, o design atual dessas estruturas é conservador, renunciando o aproveitamento da fase de encruamento do mesmo que pode levar a uma redução de seção juntamente com a redução do peso da estrutura e economia - sem comprometer a segurança para os usuários.

\section{METODOLOGIA}

Este artigo é resultado da organização dos estudos desenvolvidos nos projetos de extensão "Uso do Aço Inoxidável na Construção Civil" e "Método da Resistência Contínua" que foram apresentados para a Semana de Ensino, Pesquisa e Extensão do Centro Federal de Educação Tecnológica Celso Suckow da Fonseca, o CEFET-RJ. Sua metodologia consistiu em revisão bibliográfica, fazendo uso de informações obtidas em sites, artigos, dissertações de mestrado, teses de doutorado, trabalhos de conclusão de curso e materiais acadêmicos diversos como aulas disponíveis na internet e palestras em congressos de engenharia estrutural. Primeiramente, serão esclarecidas, de maneira sucinta e didática, as características do material estudado para,

\footnotetext{
${ }^{1}$ Disponível em: <https://www.goldengate.org/exhibits/fog-steel-salt-rust-and-paint/>. Acesso em: 25 de set. de 2019. ${ }^{2}$ SANTOS, J. Comportamento Estrutural de Elementos em Aço Inoxidável. Dissertação (Mestrado em Engenharia Civil) Programa de Pós-Graduação em Engenharia Civil, UERJ. Rio de Janeiro, 2008.
} 
posteriormente, apresentar a problemática, a solução proposta, um breve resumo de resultados experimentais obtidos e algumas conclusões, a partir do Método da Resistência Contínua.

\section{DESENVOLVIMENTO}

\subsection{Introdução ao Material}

O aço inoxidável apresenta diversas vantagens em relação ao aço carbono que levam à sua elevada durabilidade. Entre elas estão: resistência à corrosão, elevada resistência mecânica, resistência ao fogo, reduzida necessidade de manutenção e estética. Sobre a primeira, o material, em contato com o oxigênio do ar, forma, graças ao cromo em sua constituição, um filme de óxido que o protege contra a corrosão, permitindo, assim, apenas por conta dessa característica, seções menores (sem a necessidade de considerar um aumento para servir de sacrifício à corrosão). Quanto a sua constituição básica, este material é uma liga metálica que precisa apresentar pelo menos $12 \%$ de cromo para ser considerado inoxidável e que pode ter a adição de outras possíveis substâncias em sua formação - como níquel, carbono, silício etc. - diferenciando os tipos de aços inoxidáveis entre si. Eles podem ser classificados em cinco grupos principais: austenítico, ferrítico, martensítico, duplex e preciptation hardening, dependendo dos teores de cromo, níquel, carbono e outros elementos de liga.

Quadro 2: Nomenclatura

\begin{tabular}{|c|c|c|}
\hline Tipo & Composição Básica & Aplicações \\
\hline Austenítico & Cromo (18\%), níquel (8\%); & $\begin{array}{l}\text { Indústria (química, petroquímica, } \\
\text { farmacêutica etc.), construção civil; }\end{array}$ \\
\hline Ferrítico & Cromo (16-30\%), baixo carbono, sem níquel; & $\begin{array}{c}\text { Eletrodomésticos, moedas, talheres, } \\
\text { indústria automobilística; }\end{array}$ \\
\hline Martensítico & $\begin{array}{l}\text { Cromo (até } 18 \% \text { ), maior teor de carbono que os } \\
\text { ferríticos, sem níquel; }\end{array}$ & $\begin{array}{c}\text { Facas, bisturis, pinças, materiais que exigem } \\
\text { alta temperabilidade; }\end{array}$ \\
\hline Duplex & Mistura austenítica e ferrítica; & Dutos, evaporadores, destiladores, tanques; \\
\hline $\begin{array}{l}\text { Preciptation } \\
\text { Hardening }\end{array}$ & $\begin{array}{l}\text { Cromo (17\%), níquel (7\%), alumínio, cobre, } \\
\text { titânio, molibdénio (pequenas quantidades dos } \\
\text { últimos). }\end{array}$ & Indústria (diversas). \\
\hline
\end{tabular}

Fonte: (UFPR e SID INOX, s.d.). 
Os aços inoxidáveis recomendados para utilização em estruturas são os tipos austenítico S304, ferrítico 430 e duplex $2205^{3}$ devido à sua alta ductilidade, que é a capacidade de deformação do material sem que ocorra a ruptura. Já os aços inoxidáveis dos tipos martensítico e preciptation hardening apresentam também uma alta resistência, mas, pela sua pouca deformação, têm uma ruptura brusca sem que a estrutura apresente previamente sinais mais perceptíveis de que está próxima ao colapso (ver curva do aço martensítico na Figura 1).

Figura 1: Comparativo do Comportamento Mecânico dos Tipos de Aço Inoxidável

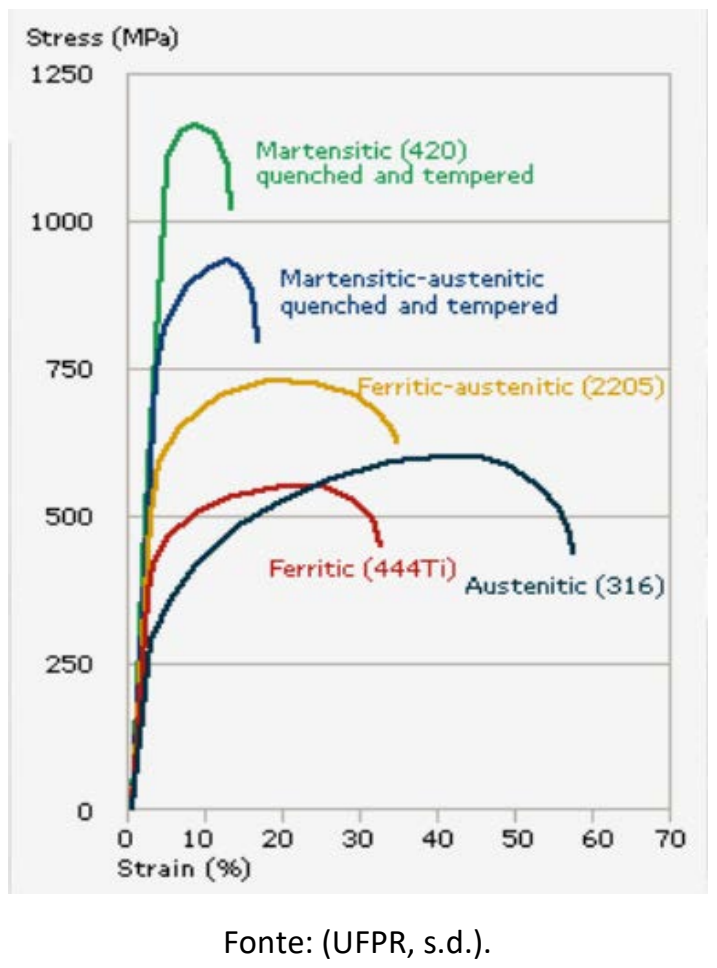

\subsection{Problemática}

As normas de cálculo atuais para estruturas em aço inoxidável - tendo como principal referência neste trabalho a norma europeia Eurocode 3 - são desenvolvidas por analogias ao comportamento do aço carbono. No entanto, o aço carbono é um metal cujo comportamento mecânico, demonstrado na sua curva tensão-deformação, apresenta um resultado completamente diferente do aço inoxidável. Ou seja, o material percorre o trecho elástico em que a deformação aumenta de maneira proporcional à tensão aplicada - podendo assim, pela Lei de Hooke, definir o seu módulo de elasticidade - para então chegar a uma tensão em que o material começa o trecho

\footnotetext{
${ }^{3}$ SANTOS, J. Comportamento Estrutural de Elementos em Aço Inoxidável. Dissertação (Mestrado em Engenharia Civil) Programa de Pós-Graduação em Engenharia Civil, UERJ. Rio de Janeiro, 2008.
} 
plástico e passa a sofrer deformações permanentes - residuais - até a sua ruptura. Essa tensão de transição entre o trecho elástico e o trecho plástico é denominada limite de escoamento. Além disso, o aço carbono também apresenta um patamar de escoamento que é o momento no qual o aço continua sofrendo uma grande deformação, sem aumento de tensão, formando uma espécie de platô no seu gráfico (ver Figura 2 e Figura 3).

A curva tensão-deformação do aço inoxidável não apresenta um patamar de escoamento, logo, também não tem uma tensão limite de escoamento definida pelo resultado da sua curva. Dessa maneira, segundo a norma, o método a seguir-se, a fim de obter um valor para a tensão limite de escoamento a ser considerada nesses casos, é encontrar o ponto de interseção entre a curva do material e uma reta paralela ao trecho elástico (mesma inclinação do módulo de elasticidade) passando a $0.2 \%$ da deformação específica - no eixo das abscissas.

Por conta disso, o dimensionamento atual desconsidera o aumento de resistência e dureza a frio que o aço inoxidável sofre, enquanto a tensão é aplicada, limitando, assim, a sua resistência ao limite de escoamento estimado. Essa deformação sofrida que leva ao aumento da dureza e resistência do material - processo conhecido como encruamento - é elevada no caso do aço inoxidável, devido à sua alta ductilidade que permite que ele deforme sem ocorrer a ruptura da peça.

Figura 2: Curvas tensão-deformação com e sem patamar de escoamento

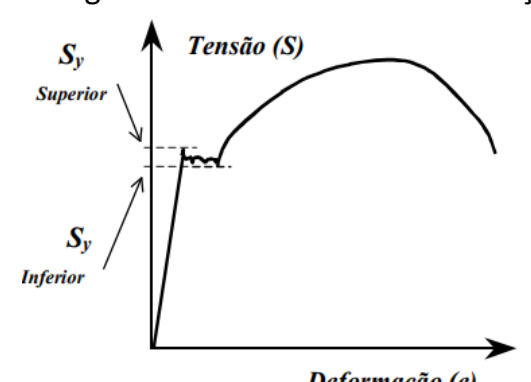

Deformação (e)

Fonte: (NETO, 2006).

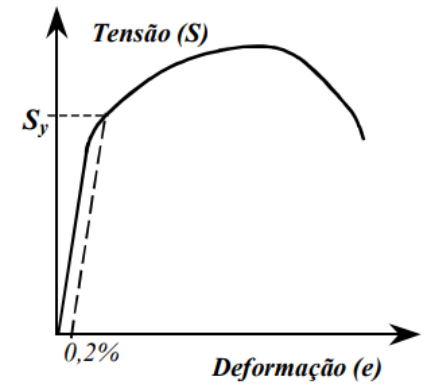

Deformação (e)

Figura 3: Curva Aço Inoxidável vs. Aço Carbono Sobrepostas

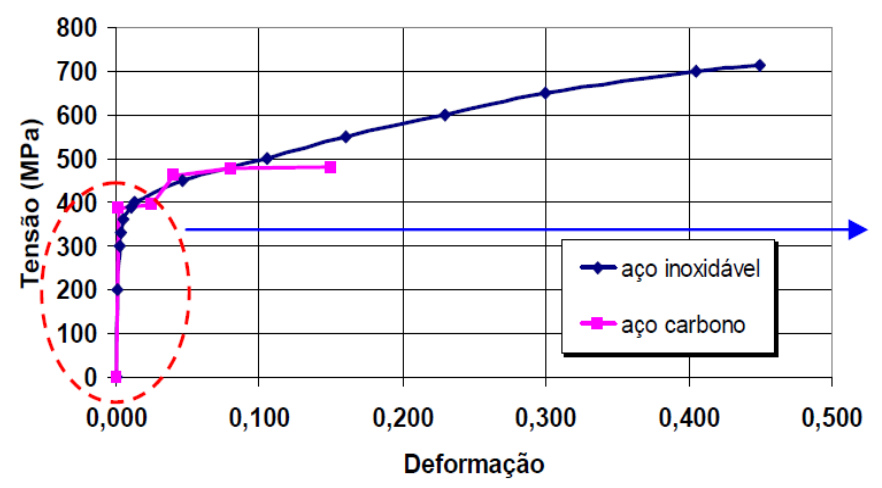

Fonte: (SANTOS, 2008).

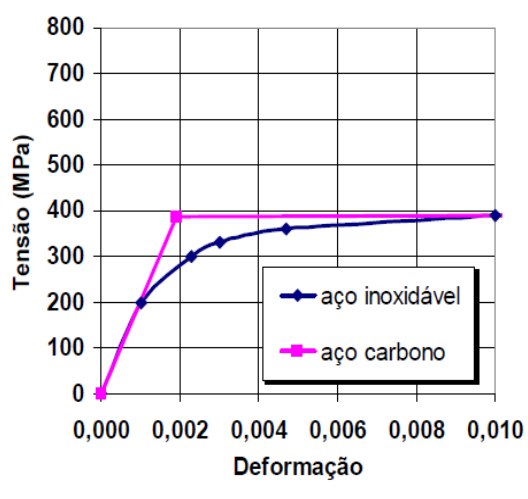


O Método da Resistência Contínua considera que a resistência do material é adquirida continuamente na deformação dele, de maneira que este metal poderia ser melhor aproveitado e seu alto valor compensado.

\subsection{Classificação da Seção Transversal e Resultados Experimentais}

No artigo "The Continuous Strength Method for Structural Stainless Steel Design" ${ }^{4}$, os pesquisadores Sheida Afshan e Leroy Gardner explicam que o Método da Resistência Contínua muda a lógica de classificação da seção transversal - que lida com o valor da tensão limite de escoamento em sua metodologia - pela ideia de capacidade de deformação da seção, e substitui um modelo erroneamente assumido para fins de cálculo como elástico e perfeitamente plástico por um modelo de material que permita o endurecimento por encruamento.

A classificação pela seção transversal é a forma como a Eurocode determina a resistência estrutural do design e prevê flambagens locais na seção (pois antes que ocorra a flambagem de toda a peça, podem ocorrer deformações localizadas). Primeiramente, mede-se a largura da alma até a ponta da aba em uma seção I ou o comprimento interno em uma seção vazada, ou o diâmetro externo de uma seção circular. Depois, divide-se esse valor pela espessura da peça. Por fim, devese garantir que essa razão seja menor que $\varepsilon$, que depende da tensão limite de escoamento do material $\left(f_{y}\right)$ :

$$
\varepsilon=\sqrt{\frac{235}{f_{y}}}
$$

Os limites entre as classes de seções dependem do fator $\varepsilon$ (épsilon) que é calculado pela fórmula acima (se fosse pela norma britânica, o valor 235 seria substituído por 275). Se o resultado for um valor bem abaixo de $\varepsilon$, então a seção será classificada como Classe 1. Logo, quanto maior o resultado dessa razão, maior será a classificação da seção, e o entendimento do seu comportamento muda. Segundo a Eurocode 3 Parte 1-1 5.5.2:

a) Classe 1: seções que podem formar uma dobra plástica com capacidade de rotação total sem redução da resistência;

\footnotetext{
${ }^{4}$ GARDNER, L.; AFSHAN, S. The Continuous Strength Method for Structural Stainless Steel Design. Thin-Walled Structures, Londres, Julho 2013.
} 
b) Classe 2: seções que desenvolvem sua resistência ao trecho plástico, mas com limitações na sua rotação, devido à flambagem local;

c) Classe 3: seções em que as fibras do aço podem alcançar sua distribuição elástica de tensões total e atingir a tensão de escoamento; porém sem oferecer resistência ao trecho plástico, devido à flambagem local;

d) Classe 4: seções em que a flambagem local ocorre antes de atingir a tensão de escoamento.

A classificação da seção transversal é o modo atual de consideração da flambagem local em seções metálicas e é usada para determinar o design apropriado para a resistência das peças em aço. A norma continua instruindo a como utilizar essa classificação para determinar valores essenciais ao dimensionamento, como a resistência à flexão da peça.

Esse método é adequado para materiais em que a tensão de escoamento " $\mathrm{f}_{\mathrm{y}}$ " é bem definida, devido à existência do patamar de escoamento, permitindo que essas seções sejam divididas em classes de comportamento discretas. Gardner e Theofanous, baseados em dados experimentais, mostraram que a atual classificação é conservadora, superdimensionando as estruturas que serão feitas em um material que já tem preço mais elevado.

$\mathrm{Na}$ imagem abaixo, a linha vertical pontilhada delimita o limite entre seções robustas e esbeltas, pois, à esquerda dela, o valor da carga última experimental ( $\mathrm{N}_{\mathrm{u}, \text { test }}$ ) é superior ao valor limitante atual - a tensão de escoamento determinada pela norma -. Pode-se verificar que é nas seções mais robustas que os resultados experimentais, no aço inoxidável, mostraram maior diferença entre os obtidos pela norma europeia.

Figura 4: Comparativo entre previsão da norma e dados experimentais para colunas segundo sua a esbeltez

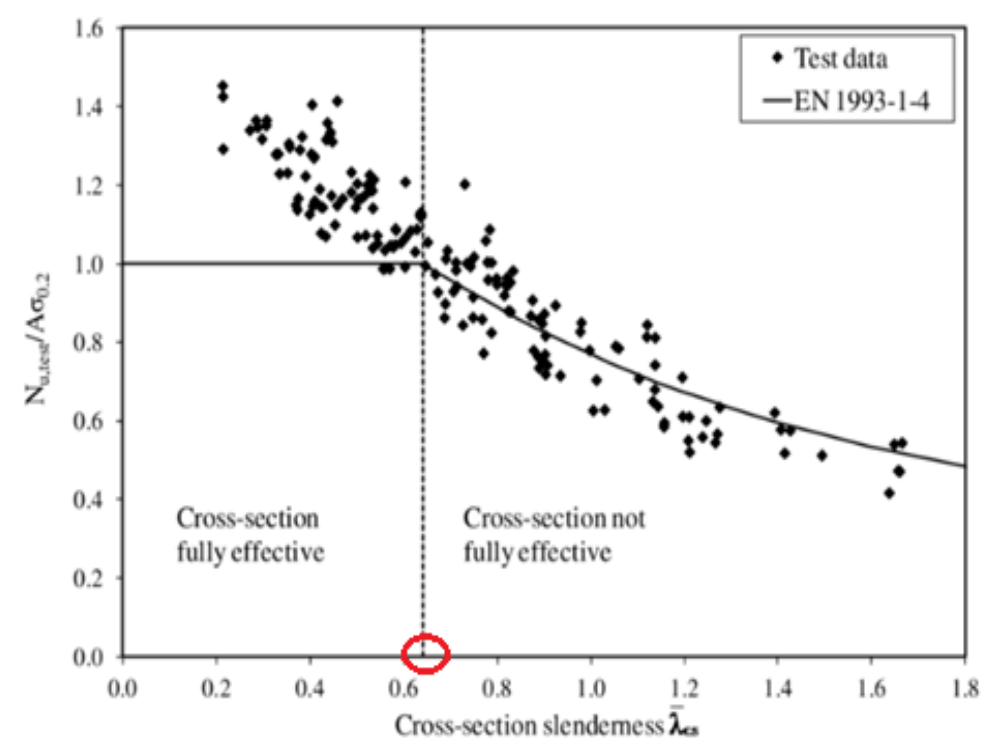

Fonte: (AFSHAN e GARDNER, 2013). 
Em pesquisas recentes, conduzidas pelo professor DSc. João de Jesus dos Santos, na Universidade do Estado do Rio de Janeiro e na Pontifícia Universidade Católica do Rio de Janeiro, é possível conferir grandes diferenças entre os resultados experimentais e os esperados pelo método normativo.

Os ensaios consistiram na aplicação de uma força que tracionasse chapas de aço inoxidáveis aparafusadas. Para isto, também foi utilizada uma chapa de aço carbono que transmitia esses esforços para as chapas de aço inoxidável austenítico S304.

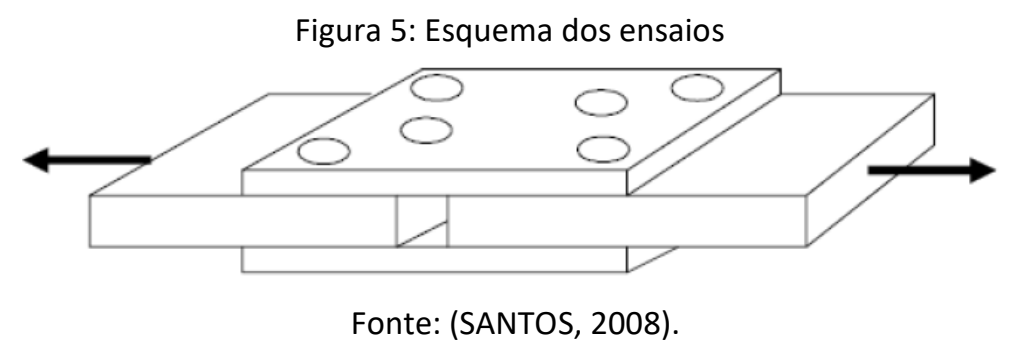

Na Figura 8, é possível conferir as diferenças percentuais que cada teste apresentou em relação ao cálculo feito pela Eurocode 3 para a carga última de ruptura.

No Quadro 3 e nas Figuras 6 e 7, é possível consultar o esclarecimento sobre a nomenclatura dos ensaios.

Quadro 3: Nomenclatura

\begin{tabular}{|l|l|}
\hline \multicolumn{2}{|c|}{ Nomenclatura dos Ensaios } \\
\hline E & Ensaio \\
\hline 1 & Número do ensaio \\
\hline CARB & Aço carbono \\
\hline INOX & Aço inoxidável \\
\hline S50 & $\begin{array}{l}\text { Parâmetro da geometria da chapa aparafusada, em mm (ver Figura } \\
6)\end{array}$ \\
\hline P10 & Espessura da placa, quando não for de 15 mm \\
\hline a & $\begin{array}{l}\text { Configuração dos furos nas chapas, quando não for do tipo "b" (ver } \\
\text { Figura 7) }\end{array}$ \\
\hline
\end{tabular}

Fonte: (SANTOS, 2008). 
Figura 6: Parâmetro S - parafusos alternados

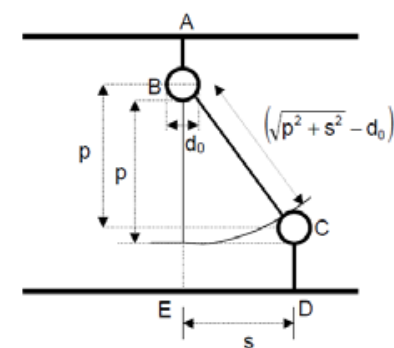

Fonte: (COCHRANE, 1922).

Figura 7: Possíveis configurações da ligação aparafusada

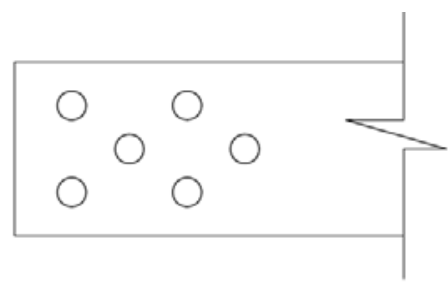

Tipo A

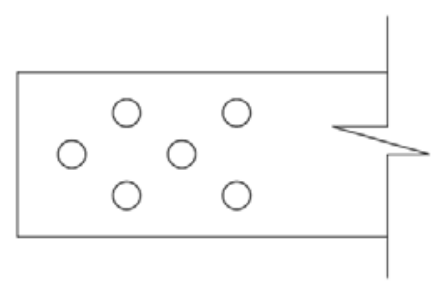

Tipo B

Fonte: (SANTOS, 2008).

Verificou-se que os ensaios feitos com o aço inoxidável apresentaram todos pelo menos $40 \%$ a mais que o esperado por norma e, chegando a até quase $60 \%$ a mais, mostrando assim o conservadorismo que a metodologia atual leva.

Figura 8: Diferença entre resultado experimental e resultado normalizado

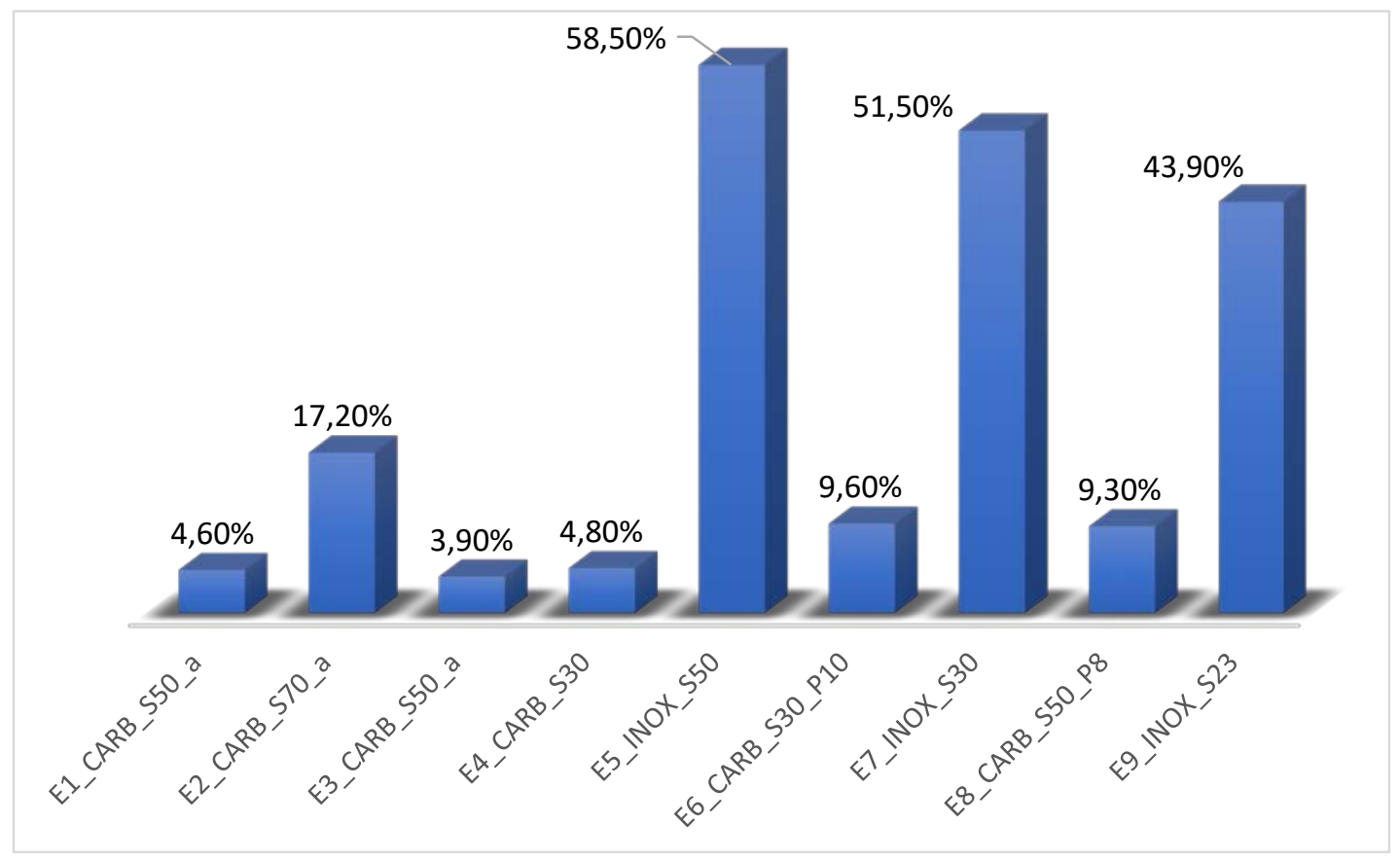

Fonte: (SANTOS, 2008). 
Já resultados comparativos desenvolvidos posteriormente mostram que essa diferença é ainda mais acentuada se o aço inoxidável, em questão, for especificamente do tipo austenítico:

Figura 9. Tensão limite de escoamento para diferentes tipos de aço pelo MRC e pela Eurocode

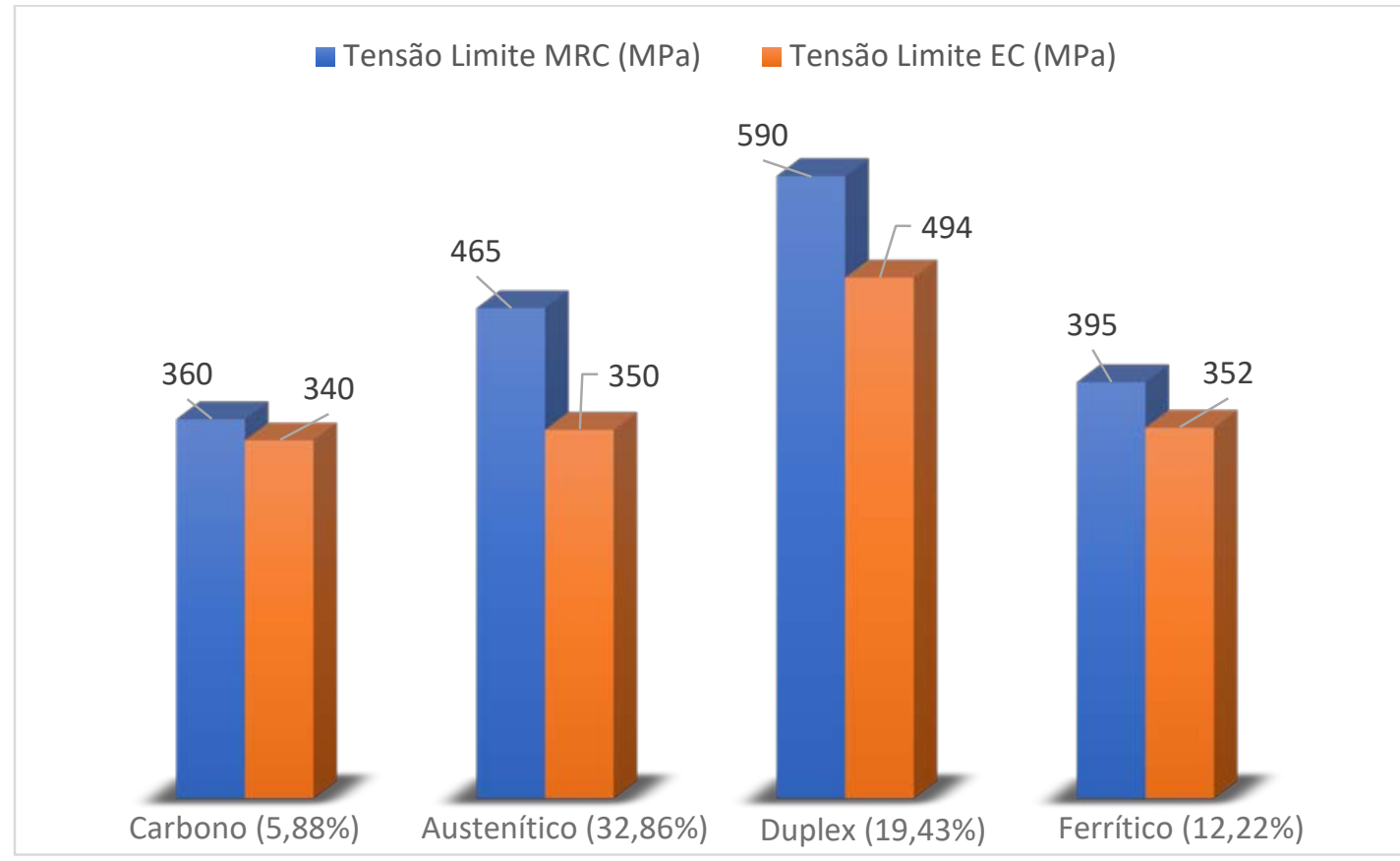

Fonte: (SANTOS, 2014).

\subsection{O Método da Resistência Contínua}

O Método da Resistência Contínua (MRC) é um método baseado nas deformações do material, utilizando uma curva-base que define o nível de deformação que a seção suporta, e um material modelo que permite que o elevado endurecimento por encruamento do material ocorra. Há, no método, a relação entre resistência da seção e sua capacidade de deformação que, por sua vez, é função da sua esbeltez e susceptibilidade a flambagem local; pois a capacidade de deformação da seção transversal traduz a habilidade dela de produzir o endurecimento por encruamento, suportando aumentos de tensão, que aumenta a resistência a frio da peça.

Primeiras versões do MRC utilizavam o material modelo de Ramberg-Osgood que apresenta equações complexas. Entretanto, um material modelo mais simples, com expressões mais razoáveis, pode ser obtido para uso nas normas. O método, então, considera um comportamento elástico com endurecimento linear. 
Após desenvolvimento, a tensão última desse material $\left(f_{u}\right)$ é dada pela primeira equação abaixo, e a deformação específica do material na tensão última $\left(\varepsilon_{u}\right)$ é e dada pela segunda equação (encontradas no anexo C da EN 1993 1-4):

$$
\begin{gathered}
E_{s h}=\frac{f_{u}-f_{y}}{0,16 \varepsilon_{u}-\left(\varepsilon_{y}+0,002\right)} \\
\varepsilon_{u}=1-\frac{f_{y}}{f_{u}}
\end{gathered}
$$

Na Figura 10, há um comparativo entre o material modelo empregado na proposta atual (simplificado) e o material-modelo anterior de Ramberg-Osgood:

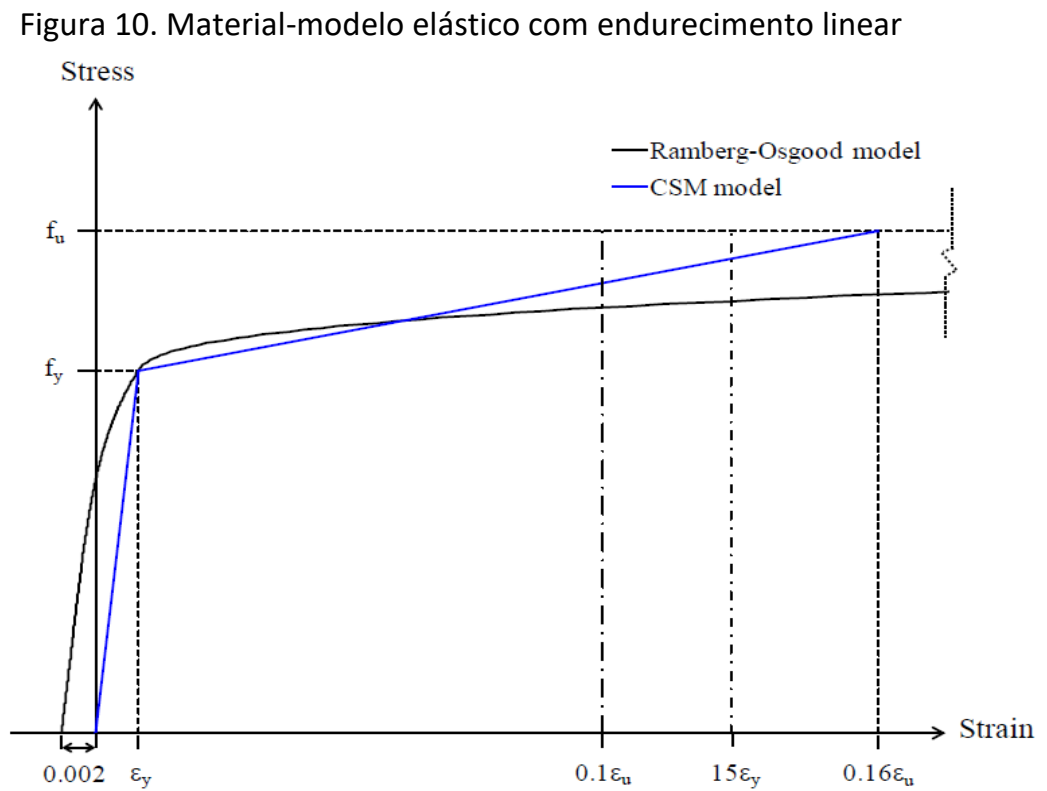

Fonte: (AFSHAN e GARDNER, 2013)

\section{CONSIDERAÇÕES FINAIS}

Os resultados aqui expostos mostram que os critérios atuais de projeto precisam ser revistos e mais estudos voltados para a compreensão desse material devem ser conduzidos, a fim de proporcionar melhores condições - especialmente econômicas - para o uso dele na construção civil. 
A partir das relações desenvolvidas para a capacidade de deformação da seção, a tensão limite também pode ser encontrada. Essa é a ideia principal do Método da Resistência Contínua: elaborar - para um material em que a deformação sofrida é importante para a sua resistência - um método de cálculo que foque na deformação limite para, assim, por fim, achar a tensão limite correspondente.

Os experimentos com chapas de aço inoxidável aparafusadas submetidas à tração mencionados neste artigo apresentaram grandes deformações e maior razão entre a tensão última e a tensão limite de escoamento $\left(f_{u} / f_{y}\right)$. Esta razão - cerca de $60 \%$ maior que a do aço carbono indica uma maior capacidade de absorver energia e de se beneficiar com o endurecimento por encruamento. Portanto, gera maior resistência na fase plástica do material, aumentando a carga última de ruptura.

A tensão última de ruptura dos ensaios em aço inoxidável possui valores consideravelmente superiores aos esperados pela Eurocode. Dessa forma, o cálculo normativo resulta em um superdimensionamento em prol da segurança, evitando as deformações, mas ignorando a real capacidade de carga do material.

Por fim, o Método da Resistência Contínua é um método inovador e promissor para chegar à previsão da carga última que o material resiste, pois apresenta melhores resultados, considerando o comportamento mecânico do aço inoxidável.

\section{REFERÊNCIAS}

AISC American Institute of Steel Construction Design Guide 30: Structural Stainless Steel.; 2012. BELLEI, I. H.; PINHO, F. O.; PINHO, M. O. Edifícios de Múltiplos Andares em Aço. São Paulo: PINI, 2004.

BRESCIANI, E. et al. Conformação Plástica dos Metais. Editora da Unicamp, Campinas, n. 5, Maio de 2011.

COCHRANE, R. article, Engineering News, 1922.

EUROCODE 3, ENV - 1993-1-1: Design of steel structures - Part 1-1: General rules and rules for buildings. CEN, European Committee for Standardisation, Brussels, 2003.

EUROCODE 3, prEN - 1993 - 1-4: Design of steel structures - Part 1-5: Design of steel structures Plated structural elements. CEN, European Committee for Standardisation, Brussels, 2006.

EUROCODE 3, prEN - 1993-1-4: Design of steel structures - Part 1-4: General rules - Stainless Steel. CEN, European Committee for Standardisation, Brussels, 2003. 
FIRE SUN. Steel Design - Section Classification and Local Buckling - SD424. Youtube, 29 de jan. de 2020. Disponível em: <https://www.youtube.com/watch?v=|8-0hPLjuPw>. Acesso em: 20 de jul. de 2021.

FOG, STEEL, SALT, RUST AND PAINT. Golden Gate Bridge: Highway \& Transportation District, s.d. Página Inicial. Disponível em: <https://www.goldengate.org/exhibits/fog-steel-salt-rust-andpaint/>. Acesso em: 25 de set. de 2019.

GARDNER, L.; AFSHAN, S. The Continuous Strength Method for Structural Stainless Steel Design. Thin-Walled Structures, Londres, Julho 2013.

GARDNER, L.; THEOFANOUS, M. Discrete and continuous treatment of local buckling in stainless teel elements. Journal of Constructional Steel Research, Londres, Novembro 2008. ISSN 11.

INFORMAÇÕES TÉCNICAS AÇO INOXIDÁVEL. Sid Açolnox, 2020. Página Inicial. Disponível em: <https://sidacoinox.com.br/informacoes-tecnicas-aco-inoxidavel/>. Acesso em: 03 de ago. de 2021.

NETO, C.L. Simulação numérica da laminação a frio no laminador Sendzimir número 2 da Acesita. Dissertação (Mestrado em Engenharia Metalúrgica). Programa de Pós-Graduação em Engenharia Metalúrgica e de Minas, UFMG. Belo Horizonte, 2006.

SANTOS, J. Comportamento Estrutural de Elementos em Aço Inoxidável. Dissertação (Mestrado em Engenharia Civil) - Programa de Pós-Graduação em Engenharia Civil, UERJ. Rio de Janeiro, 2008.

SANTOS, J. Estudo Experimental de Ligações Aparafusadas de Aço Inoxidável Submetidas à Tração. Tese (Doutorado em Engenharia Civil) - Programa de Pós-Graduação em Engenharia Civil, PUC-Rio. Rio de Janeiro, 2014.

SOUZA, J. F. Estudo para Diminuição do Grau de Redução por Passe na Laminação a Frio de um Fio de Aço Baixo Carbono. 2013. Trabalho de Conclusão de Curso (Graduação em Engenharia de Materiais) - Escola de Engenharia, Universidade Federal do Rio Grande do Sul, Porto Alegre.

THE INSTITUTION OF STRUCTURAL ENGINEERS. Stability and design of stainless steel structures. Youtube, 26 de jun. 2019.2 Disponível em: <https://www.youtube.com/watch?v=wfMkdsE2OmU\&t=130s>. Acesso em: 20 de jul. de 2021.

TIPOS DE AÇO INOX. Arinox, 2020. Página Inicial. Disponível em: <http://www.arinox.com.br/blog/os-tipos-de-aco-inox/>. Acesso em: 25 de jun. de 2021.

UNIVERSIDADE FEDERAL DO PARANÁ. Aços Inoxidáveis, s.d. Página inicial. Disponível em: <http://ftp.demec.ufpr.br/disciplinas/TM206/Prof_Marcondes/Acos\%20inoxidaveis.pdf>. Acesso em: 20 de jun. de 2021.

VP GROUNDFORCE. Classification of Steel Section. Youtube, 3 de ago. de 2016. Disponível em: <https://www.youtube.com/watch?v=RRYFEyEGo14>. Acesso em: 28 de maio de 2020.

WORLD STEEL PRICES. World Steel Prices, 2020. Página Inicial. Disponível em: <https://worldsteelprices.com>. Acesso em: 17 de jun. de 2021. 